\title{
FROM INDIVIDUALS TO POPULATIONS: PREY FISH RISK-TAKING MEDIATES MORTALITY IN WHOLE-SYSTEM EXPERIMENTS
}

\author{
Peter A. Biro, ${ }^{1,3}$ John R. Post, ${ }^{1}$ And Eric A. Parkinson ${ }^{2}$ \\ ${ }^{1}$ Division of Ecology, Department of Biological Sciences, University of Calgary, 2500 University Dr. N.W., Calgary, \\ Alberta, Canada T2N 1 N4 \\ ${ }^{2}$ British Columbia Ministry of Water, Land and Air Protection, University of British Columbia, Vancouver, \\ British Columbia, Canada V6T 1 Z4
}

\begin{abstract}
Recent research suggests that the behavior of individuals under risk of predation could be a key link between individual behavior and population and community dynamics. Yet existing theory remains largely untested at large spatial and temporal scales. We manipulated food available to age- 0 rainbow trout while at risk of cannibalism, in a replicated factorial whole-lake experiment, to test whether the trade-off between growth and mortality rates is mediated by foraging activity by young fish under predation risk. We found that this trade-off exists for young fish at the whole-system scale, and that fooddependent behavioral variation has large mortality consequences. In high-food lakes, age0 trout spent less time moving, fewer individuals swam continuously, and those swimming continuously swam at slower speeds relative to those in low-food lakes. Age-0 trout also used deep, risky habitats less when food was abundant. This lower activity, combined with avoidance of risky habitats, coincided with $68 \%$ higher survival in high-food lakes. If general, this trade-off may be a key mechanism linking individual behavior to populationlevel processes in size-structured populations.
\end{abstract}

Key words: activity; antipredator behavior; habitat use; mortality; Oncorhynchus mykiss; population consequences; predation; rainbow trout; risk-taking; trade-off.

\section{INTRODUCTION}

Models in population and community ecology have traditionally been rather phenomenalistic, abstracting considerable biological details a priori and steering empirical research toward testing model assumptions and predictions. However, the causal mechanisms included in such "top-down" models are often chosen in the absence of detailed empirical information and consequently reflect educated guesswork (Schmitz 2001). Researchers have recently argued for a more mechanistic approach that incorporates individual-level processes to determine when, and at what level of organization, they are manifest in population and community dynamics, or if they simply attenuate (e.g., Lima and Zollner 1996, Sutherland 1996, De Roos and Persson 2001, Schmitz 2001). This "bottom-up" approach has the advantage that it addresses biological complexity from the outset to determine which details are needed to describe dynamics and which can justifiably be abstracted. However, to avoid excessive model complexity it is necessary to identify important individual-level mechanisms for inclusion in these models.

For instance, the behavior of individuals while under risk of predation may be a key determinant of population and community dynamics (e.g., Turner and Mit-

Manuscript received 12 July 2002; revised 18 October 2002; accepted 11 December 2002; final version received 28 January 2003. Corresponding Editor: J. T. Wootton.

${ }^{3}$ E-mail: pbiro@ucalgary.ca telbach 1990, Huang and Sih 1991, Werner and Anholt 1996, Beckerman et al. 1997, Lima 1998, Peckarsky and McIntosh 1998, Schmitz 1998). However, there are few empirical studies that make connections between behavioral effects and population dynamics in vertebrates, and studies on antipredator behavior that suggest population-level consequences are usually based upon small-scale experiments (Lima 1998). Therefore, it remains unclear which aspects of antipredator behavior have important effects at the population and community levels. Experiments most likely to advance our understanding of the contribution of behavior to populations should quantify the effects of behavioral variation on birth, death, and growth rates, but few currently exist (Lima 1998). The lack of empirical data linking individuals and populations stems largely from the fact that experiments have not directly manipulated the behavior of interest to the extent that is possible (Anholt 1997), nor with the realism sufficient to allow results to be extrapolated to natural situations (e.g., Lima and Zollner 1996, Sutherland 1996, Fryxell and Lundberg 1997, Lima 1998). For example, antipredator responses of prey determined from small-scale experiments often overestimate the actual responses observed in the field at natural spatio-temporal scales (see Lima 1998), and therefore may overestimate consequences on growth or survival. Though logistically difficult, experimentation at the whole-system scale may be the only way to resolve extrapolation problems in some cases (see Carpenter 1996, Persson et al. 1996, 1999, Post et al. 1999). 
Recent theoretical and laboratory studies suggest that the trade-off between growth and mortality rates, mediated by prey foraging activity, may be a general mechanism for prey mortality that links individual behavior to population dynamics (e.g., Werner and Anholt 1993, Anholt and Werner 1995, 1998). The nature of the activity-mediated trade-off between growth and mortality is straightforward. Many animal taxa must move to locate and capture food, yet this movement increases encounter rates with predators and enhances predator detection (reviewed in Helfman 1990, Werner and Anholt 1993, and Lima 1998). While this activity mediated trade-off, and its potential consequences for prey mortality have been well explored in theory, it has not been empirically well studied. For instance, when growth and predation rates of model prey are functions of activity, it has been shown that, under a wide variety of fitness functions, animals should reduce their foraging effort at high levels of either factor (Abrams 1984, 1990, 1991, 1993a, b, McNamara and Houston 1987, 1994, Walters and Juanes 1993, Werner and Anholt 1993). Pool experiments with anuran larvae support the theory and show that increased activity in response to lower food abundance is associated with greater mortality (Anholt and Werner 1995), and that predation risk has smaller effects on mortality than do food effects (Anholt and Werner 1998). By contrast, foraging activity should increase with food abundance when risk is independent of activity (e.g., Dunbrack and Giguere 1987, McNamara and Houston 1994). Thus, food-dependent changes in foraging behavior provide a means of inferring when predation risk is a function of activity (Anholt and Werner 1995). Understanding the causes and consequences of antipredator behavior may provide a powerful mechanistic understanding of prey mortality, given that most animals are at the same time both predators and prey, and the qualities that make predators effective can also make them more vulnerable to predation.

In this study, we replicated whole-lake experiments to test for evidence of a decline in activity of young prey fish in response to increased food abundance, and determine whether lower activity is associated with lower mortality. We used age-0 rainbow trout (Oncorhynchus mykiss) as our prey species, adult rainbow trout as their predator, and manipulated food abundance (daphnid zooplankton) by fertilizing four of our nine lakes over an entire growing season to create a highfood treatment relative to the unmanipulated lakes. All lakes received a constant density of small adult trout representing a baseline predation risk. This was done because relatively small adult rainbow trout are the dominant predator of age-0 trout and impose high mortality (Biro et al. 2003). Young trout are risk-averse foragers, using less productive shallow habitats as a flexible response to the presence of small adult trout that inhabit more productive deep habitats (Landry et al. 1999, Biro et al. 2003). Based on theory discussed above, we expected that if the trade-off between food acquisition and mortality is indeed mediated by foraging effort, we should observe that increased food levels lead to decreased predation mortality, owing to reduced activity and use of risky habitats at higher food levels. As a secondary objective, we attempted to create variation in risk among lakes by stocking additional large adult trout to five of the lakes to test the hypothesis that large trout may impose a risk of predation that is much greater than an equal number of smaller adults (Post et al. 1999). We expected that age-0 trout would further reduce activity in the presence of large adult trout.

In addition to testing theory predicting activity responses (e.g., Werner and Anholt 1993), we also simultaneously test theory predicting that prey should use profitable but risky habitats less with increases in food (as reviewed in Lima 1998). Therefore, we predict that the trade-off between growth and mortality rates for young trout is mediated by a combination of activity and habitat use. To begin with, age- 0 trout feed on relatively sedentary daphnid zooplankton, which represents in excess of $90 \%$ of their diet (Landry 1997, Landry et al. 1999, Post et al. 1999). Therefore, increases in age- 0 trout activity should increase encounter rates with prey and increase growth rates, as it does for other young trout in still-water environments (e.g., Grant and Noakes 1987, McLaughlin et al. 1994, Biro and Ridgway 1995, Biro 1996) and movement to deep habitats provides provides access to the more abundant Daphnia in deeper habitats (Landry 1997, Landry et al. 1999). Given these facts, activity- and habitat-mediated trade-offs should exist for young trout because the likelihood of being detected and eaten by predators increases with activity in the laboratory (Dill and Fraser 1984, Metcalfe et al. 1987, Martel and Dill 1995) and with the use of deeper habitats in the field (Post et al. 1998). Our lakes are ideal for the experiment in that we are able to manipulate and replicate at the scale of entire lakes, no natural reproduction of trout occurs, and no other fish species are present. Thus, we are able to make population-level inferences about the consequences of behavioral variation among populations. Our study thus serves as an intermediate empirical test of the importance of behavior in populations, filling some of the gap between the empirically unknown effects of individual behavior on population dynamics and the short-term and small-scale experiments that fall short of linking individuals and populations in a convincing way.

\section{MethoDS}

\section{Experimental design}

We conducted a factorial experiment using nine whole lakes, and manipulated the abundance of daphnid food available to age- 0 trout by fertilizing four of the lakes, and the risk of predation by manipulating the 
TABLE 1. Treatment allocation and morphometric statistics of the nine experimental lakes.

\begin{tabular}{lccccc}
\hline \hline & \multicolumn{2}{c}{ Experimental treatment } & Surface & Maximum & Mean \\
Lake & Fertilized? & Large trout & area (ha) & $\begin{array}{c}\text { depth (m) } \\
\text { depth (m) }\end{array}$ \\
\hline BPH 1 & yes & absent & 1.9 & 7 & 2.3 \\
BPH 3 & yes & absent & 1.4 & 6 & NA \\
BPH 2 & yes & present & 1.4 & 6 & 2.8 \\
SM & yes & present & 2.0 & 8 & 3.7 \\
CPH 1 & no & absent & 4.1 & 18 & 10 \\
KPH & no & absent & 1.9 & 9 & 3.2 \\
CIG & no & present & 3.9 & 9 & 4.2 \\
K1 & no & present & 2 & 8 & NA \\
K2 & no & present & 3.2 & 14 & NA \\
\hline
\end{tabular}

Note: NA indicates unavailable data.

abundance and size structure of adult rainbow trout populations (Table 1). The experiment was conducted over an entire growing season from early summer until autumn 1999. Initial density of age-0 rainbow trout was set at 15000 trout/ha to allow us to freely sample age- 0 trout without reducing densities appreciably and to facilitate comparison with previous studies in our lakes (Biro et al. 2003). To manipulate predation risk among lakes, we stocked small-bodied age- 1 adults in all lakes (300 fish/ha) and larger age-2-3 adults in five of the lakes (65 fish/ha). Although stocked age-1 adults are relatively small at the time when age- 0 trout are stocked $(\approx 20 \mathrm{~cm}$ fork length $(\mathrm{FL})$ ), they are nonetheless cannibalistic. They induce a habitat shift of age- 0 trout into the littoral zone and impose high mortality, in contrast to when adult trout are absent (Landry 1997, Biro et al. 2003). Bird predators, by contrast, account for only a few percent of the overall mortality of age- 0 trout when at high density (Biro et al. 2003; C. Beckmann, unpublished data). Larger adult trout were used to impose an additional risk to age- 0 trout, as they are more likely to successfully capture age- 0 trout than smaller adults (e.g., Lynott et al. 1995). Therefore, we would expect these relatively few large adults to have a larger effect on age- 0 trout behavior and mortality than an equal number of small adults, as suggested by Post et al. (1999). Adult rainbow trout are not obligate piscivores and daphnid plankton and macroinvertebrates form a large proportion of their diet (Post et al. 1999). Therefore, fertilizing lakes to increase daphnid production has the potential to reduce cannibalism by adult trout if daphnids at high abundance represent a more profitable food source than young trout. If so, then risk to age- 0 trout would be reduced in fertilized lakes and consequently we expect their activity to increase. Therefore, differences in activity between age- 0 trout in fertilized and nonfertilized lakes would be reduced and thus make our test of the contribution of behavioral variation to survival a conservative one. There is little reason to believe this has occurred in our experiment given that age- 0 trout activity was significantly lower in fertilized lakes and differences in food abundance had no effect on the spatial behavior of adult trout (see Results).

\section{Field sites}

We used nine lakes located within $5 \mathrm{~km}$ of each other in south-central British Columbia, Canada $\left(49^{\circ} 50^{\prime}-\right.$ $\left.49^{\circ} 56^{\prime} \mathrm{N} ; 120^{\circ} 33^{\prime}-120^{\circ} 34^{\prime} \mathrm{W}\right)$. The lakes are $1.4-4.1$ ha in surface area, 7-15 $\mathrm{m}$ in maximum depth, and have $4-6 \mathrm{~m}$ of pelagic habitat above the thermocline (Table 1). Deeper waters were anoxic during summer stratification and unavailable to fish. The littoral habitat of the lakes consisted of open sediment, gravel, rocks, woody debris and fallen trees, and aquatic macrophytes (primarily Chara sp. and Myriophyllum sp.) occurring in patches.

In order to establish initial densities of adult trout, we sampled all lakes with gillnets with constant effort for five net-nights (see protocol below) in May 1999 to deplete survivors from previous experiments. Nets were set at midday and retrieved the following day. If no fish were caught in the first net-night, we concluded that there were no fish present because of winterkill, which was later confirmed during fall netting. Lakes with fish were netted for an additional 5-10 net-nights with $25 \%$ more gillnet until we captured less than five fish per net night. We estimated the number of survivors based upon the five-day depletion netting (see Estimation of first-season mortality and mean fall mass) minus the additional number of fish killed in subsequent netting to make small adjustments to the stocking rates of small and large adult trout. Large fish that were present in some of the lakes (CIGAR, KPH, and CP1) and were caught alive during spring netting were placed in holding pens. Fish were held for a minimum of one day before being moved to another lake or until netting was complete, if released back into the same lake. Netting and fish relocation was complete by late May. Mean fork length of the large adult trout in late May was $35 \mathrm{~cm}$ (range $=23-56 \mathrm{~cm}$ ) and mean mass was $563 \mathrm{~g}$ (range $=124-1655 \mathrm{~g})$.

\section{Fish stocks}

Rainbow trout were raised at the Fraser Valley Trout Hatchery (B.C. Fisheries Branch) from eggs collected 
from wild populations in Tzenzaicut Lake (for age-1 trout) and Tunkwa Lake (age-0 trout). Age- 0 trout were stocked within several days of completely absorbing their yolk at a mean length of $27 \mathrm{~mm}$ and mean mass of $0.152 \mathrm{~g}(n=200)$. Stocking occurred on 12 July 1999 , about the time when they emerge in nearby wild populations. To estimate stocking numbers, replicate batch samples of age- 0 trout were weighed and then all individuals were counted to obtain a mass-density. Age-0 trout dispersed around the shoreline of all lakes and were actively feeding within $24 \mathrm{~h}$ of stocking.

Small adult trout were graded into three overlapping size-classes and stocked one month prior to the introduction of age-0 trout on 7 June 1999, at a mean fork length (and mass) of $10.2 \mathrm{~cm}(12 \mathrm{~g}), 13.3 \mathrm{~cm}(25 \mathrm{~g})$ and $15.3 \mathrm{~cm}(41 \mathrm{~g} ; n=600)$. Size classes were stocked in equal proportions to achieve target densities and were counted by hand. Small adult trout grow quickly in these lakes (Post et al. 1999) and were on average $20 \mathrm{~cm}$ long at the time when age- 0 trout were stocked. By autumn, each size class reached mean lengths (and masses) of $22 \mathrm{~cm}(136 \mathrm{~g}), 25 \mathrm{~cm}(211 \mathrm{~g})$ and $27 \mathrm{~cm}$ $(256 \mathrm{~g} ; n=1655)$.

\section{Lake fertilization and food abundance}

In order to increase the abundance of daphnid zooplankton and create a food treatment, we fertilized four lakes with a 15:1 ratio of N:P using commercial liquid fertilizer. This ratio of $\mathrm{N}: \mathrm{P}$ was chosen to favor the production of edible algae and increase zooplankton productivity. We used ammonium polyphosphate solution (10-34-0) and urea ammonium nitrate solution (28-0-0); the numeric descriptors represent the percentage by mass of $\mathrm{N}, \mathrm{P}_{2} \mathrm{O}_{5}$, and $\mathrm{K}_{2} \mathrm{O}$, respectively. An initial fertilizer application was applied in early July to equalize the total phosphorus (TP) concentration in the water column among the high-food lakes. Fertilizer was then applied at a rate of $\sim 2.5 \mu \mathrm{g} / \mathrm{L}$ (based on whole-lake volume) at 1-2 week intervals throughout the experiment to achieve high and constant TP concentration. The effective fertilization rate may be considerably higher than $2.5 \mu \mathrm{g} / \mathrm{L}$ if $\mathrm{P}$ is taken up primarily in the epilimnion, as is likely to occur. We dissolved the concentrated fertilizer mix into several garbage cans of water and siphoned it slowly into the lake from a moving boat to distribute it according to relative volumes of littoral vs. pelagic habitats. Epilimnetic TP just prior to age-0 trout stocking in early July ranged from 30 to $53 \mu \mathrm{g} / \mathrm{L}$ in high-food lakes and 15-22 $\mu \mathrm{g} /$ L in low-food lakes. Early and mid-August TP in highfood lakes was 28-36 and 24-32 $\mu \mathrm{g} / \mathrm{L}$, respectively, in contrast to low-food lakes which were $12-20$ and 6-14 $\mu \mathrm{g} / \mathrm{L}$, respectively.

We assessed the success of fertilization to enhance food abundance by sampling zooplankton in three major habitats in all lakes throughout the experiment. We used six permanent sampling sites for sampling nearshore and deep littoral habitats and sampled the pelagic habitat at the lake centre. Zooplankton prey were sampled weekly in the pelagic habitat from the time of age-0 trout stocking to the end of September. Shallow and deep littoral habitats were sampled only twice in late July and in early August due to time constraints and the high effort involved in sampling these habitats. Zooplankton were sampled using a 12-L Schindler trap, as its small size (height $=0.3 \mathrm{~m}$ ) allowed sampling in shallow water. Owing to the small volume of the trap, two 12-L samples were taken adjacent to one another (separated by $\sim 1.5 \mathrm{~m}$ ) and aggregated. Nearshore littoral zooplankton was sampled at 0.50 to $0.75 \mathrm{~m}$ depth, deep littoral zooplankton was sampled at $1 \mathrm{~m}$ depth along the $2 \mathrm{~m}$ depth contour, and the pelagic habitat was sampled at 1, 3, and $5 \mathrm{~m}$ depths. The six nearshore, six deep littoral, and three pelagic zooplankton samples were combined to yield a single sample for each of the three habitats for each lake-day. Analysis involved taking a random subsample of at least 300 zooplankton, which were identified to family or genus and counted. The first 30 individuals of a given taxon encountered were measured with an eyepiece micrometer to the nearest $0.04 \mathrm{~mm}$. Biomass was estimated using density estimates and mean individual mass obtained from genus-specific length vs. wet-mass regressions from Post (1984). We present only daphnid biomass as our estimate of food abundance available to age- 0 trout, as this taxon represents $>90 \%$ of their diet (Landry 1997, Landry et al. 1999, Post et al. 1999).

\section{Behavior of individual age-O trout}

Activity of individual age- 0 trout was determined by direct observation of individuals residing in the nearshore littoral zone in mid-July (16-19 July), early August (1-4 August) and mid-August (10-13 August). Observations were made from shore with the aid of polarized glasses. Focal animal observations were made by only two observers (P. A. Biro and an assistant) between 1000 and 1630 hours in weather that was consistently bright and calm. Individual fish were selected randomly for observation several minutes after arrival at an observation location. Each observer sampled a minimum of 75 individuals per lake at 4-10 evenly spaced locations around the lake. All nine lakes were visited during a four-day period to minimize the possibility of time or ontogenetic changes in behavior among lakes during a sampling trial.

We attempted to observe each individual fish for 2.5 min but this was possible only for relatively sedentary fish. Observation duration was often much less for highly active individuals which swam at speeds up to $40 \mathrm{~cm} / \mathrm{s}$. The position of the fish at the start of the observation was noted and then the total time spent moving was measured using a stopwatch until the end of the observation period, when its final position was noted. Movement was defined as a displacement of $>0.5$ body length. Maximum displacement was measured as the linear distance between the two farthest 
positions visited by the fish by summing together the linear segments of the fish's path along and around the shoreline and shoreline debris (Biro et al. 1997). The maximum displacement over the observation period was used as an estimate of individual swimming speed for those swimming continuously. This estimates the speed well because continuously swimming individuals almost always moved in a single direction (P. A. Biro et al., personal observation).

The habitat use of age- 0 and adult rainbow trout was assessed by direct visual observation in late July and late August. The number of age- 0 and adult trout passing through a rectangular "slice" of the water column in three different depth habitats was used to estimate relative space use. The three depth habitats were $0.5-$ $1.5 \mathrm{~m}, 1.5-2.5 \mathrm{~m}$, and 3-4 m. We placed a $1 \mathrm{~m}$ long strip of flat white plastic $(5.5 \mathrm{~cm}$ wide) on the lake bottom and perpedicular to shore to guide observations. At either end of each strip was a float line to guide its placement within the appropriate depth range. Observations of the shallowest depth habitat were done from shore with the aid of polarized sunglasses. Deeper habitats were observed while lying motionless at the surface using mask and snorkel. Each observation would begin by placing the plastic strip on the bottom and then waiting 5-min before commencing observations for a 5 -min period.

In early August, we set replicate traps at three depths $(0.75,2.0$, and $3.25 \mathrm{~m}$ depths $)$ as an alternate method of determining habitat use of age- 0 trout and also to sample the size of individuals within each habitat. Each trap was made of plexiglass with a Lead-in passageway made from seine mesh and plexiglass wings that resembled a conventional trap net but was only $40 \mathrm{~cm}$ in height. One trap was set at each depth simultaneously for one hour so that the mouths of the traps were all facing the same direction along their respective depth contour and the net leading to the trap lay along that depth contour. This procedure was repeated twice for each lake.

\section{Growth}

Growth of age- 0 trout during the summer was estimated using the mean mass of individuals captured by beach seine in late July and late August. We sampled all nine lakes over four days using a 20 -m beach seine that sampled to a depth of $2 \mathrm{~m}$. The net was set in a $\mathrm{J}$ shape to fence off a short section of shoreline; we then used a boat, a swimmer, and another person walking in shallow water to chase age- 0 trout into the waiting beach seine that was closed shut by a fourth person. Use of a boat and an oar lowered to a depth of $2 \mathrm{~m}$ allowed us to chase fish from $2-4 \mathrm{~m}$ depth into the beach seine. We sampled fish from several locations around the shoreline of each lake, which typically yielded a total of not less than 1000 fish; these were then held in an oxygenated cooler. We then randomly subsampled 200 individuals for length and mass measurement.

\section{Estimation of first-season mortality and mean fall mass}

We used lethal gillnet sampling during the first 2.5 wk of October to estimate fall population size. Gillnet densities were standardized among lakes based on lake area and ranged from 400 to $500 \mathrm{~m}^{2} \cdot \mathrm{ha}^{-1} \cdot$ night $^{-1}$, following the identical netting effort and protocol used by Post et al. (1999) in these same lakes. We set sinking and floating experimental gillnets with graded mesh from 13 to $89 \mathrm{~mm}$ (stretched mesh size) for five nights in all habitats. Nets were set during the day and retrieved $24 \mathrm{~h}$ later. The summed catch over five nights of netting was adjusted to account for the fact that the smallest fish are caught with much lower probability than large fish (Post et al. 1999). To do this, we estimated a mean capture probability model that expresses the proportion of fish of a particular size that are captured over the five nights of netting (A. J. Paul, unpublished data). This model was estimated from mark and recapture data collected in 1993 and 1994 in these same lakes. A total of 7503 fish ranging in size from 50 to $328 \mathrm{~mm}$ fork length were captured, marked, and released just prior to fall netting in a number of lakes with age- 0 trout density varying from 500 to 12000 trout/ha. The proportion of marked fish in each $5-\mathrm{mm}$ size interval recaptured over the five nights of netting follows a binomial probability distribution into which we could substitute various models that could predict the probability of capture, given $r$ recaptures and $n$ marked fish. The most likely model describing the data was determined by maximum likelihood and comparison of $\mathrm{AIC}_{\mathrm{c}}$ statistics for each (Burnham and Anderson 1998; see Statistical analysis). The most parsimonious model was a four-parameter logistic function of the following form:

$$
P_{\text {capture }}=0.431 \times \frac{1}{\left[1+e^{(1.36-1.18 \mathrm{FL})}\right]^{0.02}}
$$

where $P_{\text {capture }}$ is the proportion of fish of a given fork length (FL, in millimeters) captured over five nights of gillnetting. This function describes a steeply increasing function between 50 and $125 \mathrm{~mm}$ in length, and then a constant capture probability for fish $>125 \mathrm{~mm}$ in length (A. J. Paul, unpublished data). To estimate mean fall mass, we divided the length catch data into bins containing the catch within $10-\mathrm{mm}$ increments in FL, calculated the mean mass in each, and multiplied these values by the estimated number of survivors in each size bin.

\section{Statistical analysis}

We analyzed variation in daphnid abundance, adult trout distribution, age- 0 trout behavior, growth, and mortality using general linear models with fertilization and adult size-structure treatments (and interactions) 
as predictor variables. Working at the scale of whole systems, with few replicates, results in the loss of statistical power and an increased Type II error rate, particularly when using traditional parametric statistics. Therefore, we used maximum-likelihood techniques to find the most likely model given the data rather than relax the traditional (and arbitrary) level of significance of $\alpha=0.05$ (Hilborn and Mangel 1997, Burnham and Anderson 1998). We used a type III likelihood-ratio (LR) test for nested models where one parameter at a time is removed from the saturated model. This test is asymptotically $\chi^{2}$ distributed with degrees of freedom equal to the difference between the degrees of freedom of the more complex model and the less complex model. We also used a modified Akaike information criterion $\left(\mathrm{AIC}_{\mathrm{c}}\right)$ for model selection in one particular analysis where this slightly more powerful test identified a significant effect, and the equivalent LR test did not. The model with the smallest value of $\mathrm{AIC}_{\mathrm{c}}$ represents the most likely model, given the data. This optimization criterion offers a relative measure of support for nested or unested models where competing models can be ranked relative to the best supported model, where $\Delta_{i}$ $=\mathrm{AIC}_{\mathrm{cobserved}}-\mathrm{AIC}_{\mathrm{c} \text { minimum }}$. Therefore, the most likely model has $\Delta_{i}=0$, and competing models with $\Delta_{i}<3$ are essentially equally probable (Burnham and Anderson 1998). In addition to our likelihood analyses, we also present parametric $R^{2}$ values to express effect sizes for likely models. We used PROC GENMOD for maximum-likelihood analyses and PROC GLM to obtain $R^{2}$ values (SAS Institute 1998).

Age-0 trout mortality, the proportion of time spent moving by young trout, and the proportion of trout observed at different depths were analyzed assuming normally distributed errors on arcsine square-root transformed data. The proportion of each age- 0 trout cohort that was continuously active was modelled assuming binomially distributed errors on the raw data. The speed of continuously active individuals was $\log _{e}$ transformed. We arsine square-root transformed all dependent variables that were expressed as a proportion and log-transformed continuous variables.

\section{RESULTS}

\section{Distribution and abundance of food resources}

The experimental addition of fertilizer was successful in creating nonoverlapping daphnid food abundance treatments (Fig. 1). Mean Daphnia biomass over the season was significantly greater in fertilized than in unfertilized lakes in shallow littoral, deep littoral, and pelagic habitats $\left(\chi_{1}^{2}=25,6.6\right.$, and 16 , respectively, $P$ $<0.01$ in each case). The fitted models estimate that daphnid biomass in the nearshore habitat was 54 times greater in fertilized than in unfertilized lakes $(200 \mu \mathrm{g} /$ $\mathrm{L}$ and $3.7 \mu \mathrm{g} / \mathrm{L}$, respectively; Fig. 1). In deep littoral habitats, estimated daphnid biomass was four times greater in fertilized lakes than in unfertilized lakes

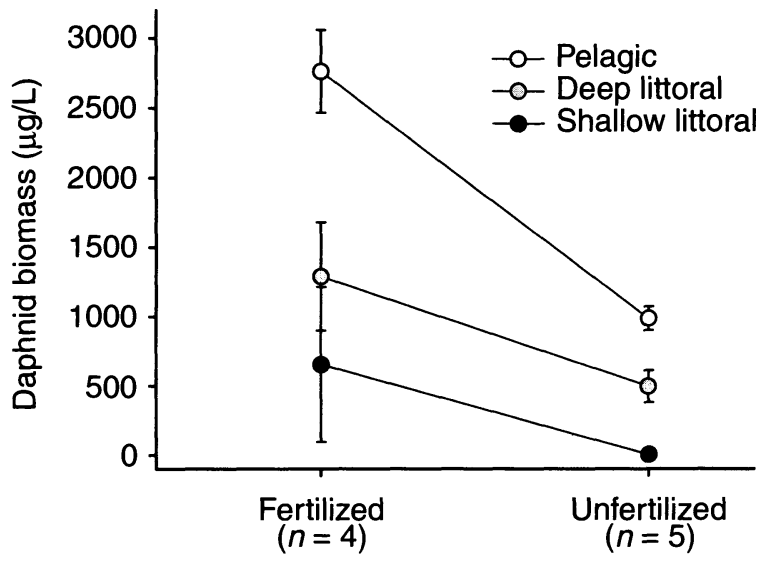

Food treatment

FIG. 1. Mean daphnid biomass in the nearshore littoral, deep-littoral, and pelagic habitats in relation to the experimental fertilization treatment. Error bars indicate \pm 1 SE. Sample size for each estimate on the raw data is given.

(1120 $\mu \mathrm{g} / \mathrm{L}$ and $305 \mu \mathrm{g} / \mathrm{L}$, respectively), and in pelagic habitats was 2.7 times greater $(2725 \mu \mathrm{g} / \mathrm{L}$ and $975 \mu \mathrm{g} /$ $\mathrm{L}$, respectively). Daphnid biomass was more abundant in deep than in shallow habitats, as is characteristic of lakes in general (Fig. 1; see also Wetzel 1983).

\section{Distribution of adult trout within lakes and among treatments}

Risk of encountering adult trout predators by age- 0 trout was higher in deep than in shallow habitats within any given lake, but adult trout distribution did not differ among treatments (Fig. 2). A significantly higher proportion of adult trout were observed in deep than in shallow habitats in July and in August $\left(\chi_{1}^{2}=16.6\right.$ and 11.5 , respectively, both $P<0.005$ ). Adult trout distribution was not affected by population size-structure, fertilization, or the interactions $\left(\chi_{1}^{2}<4\right.$ and $P>0.15$

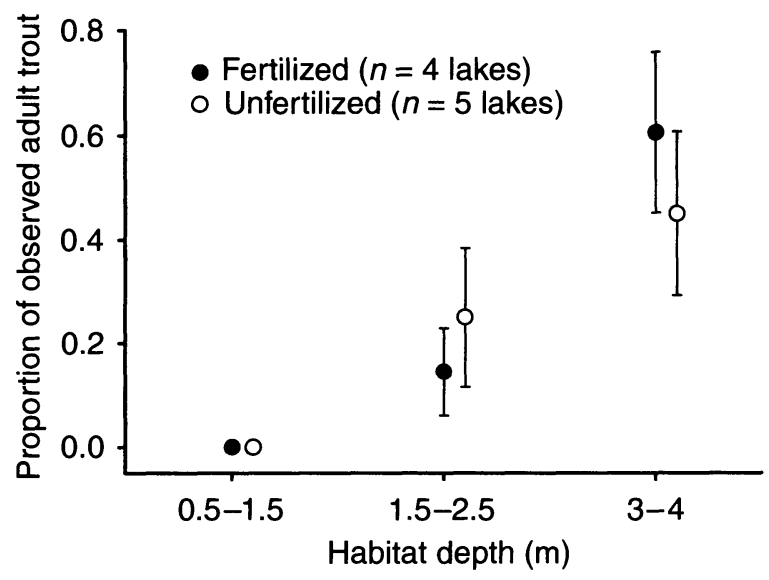

FIG. 2. Mean proportion of adult trout observed at different depths. Error bars indicate $\pm 1 \mathrm{SE}$. Sample size for each estimate on the raw data is given, averaged across the adult trout treatment. 


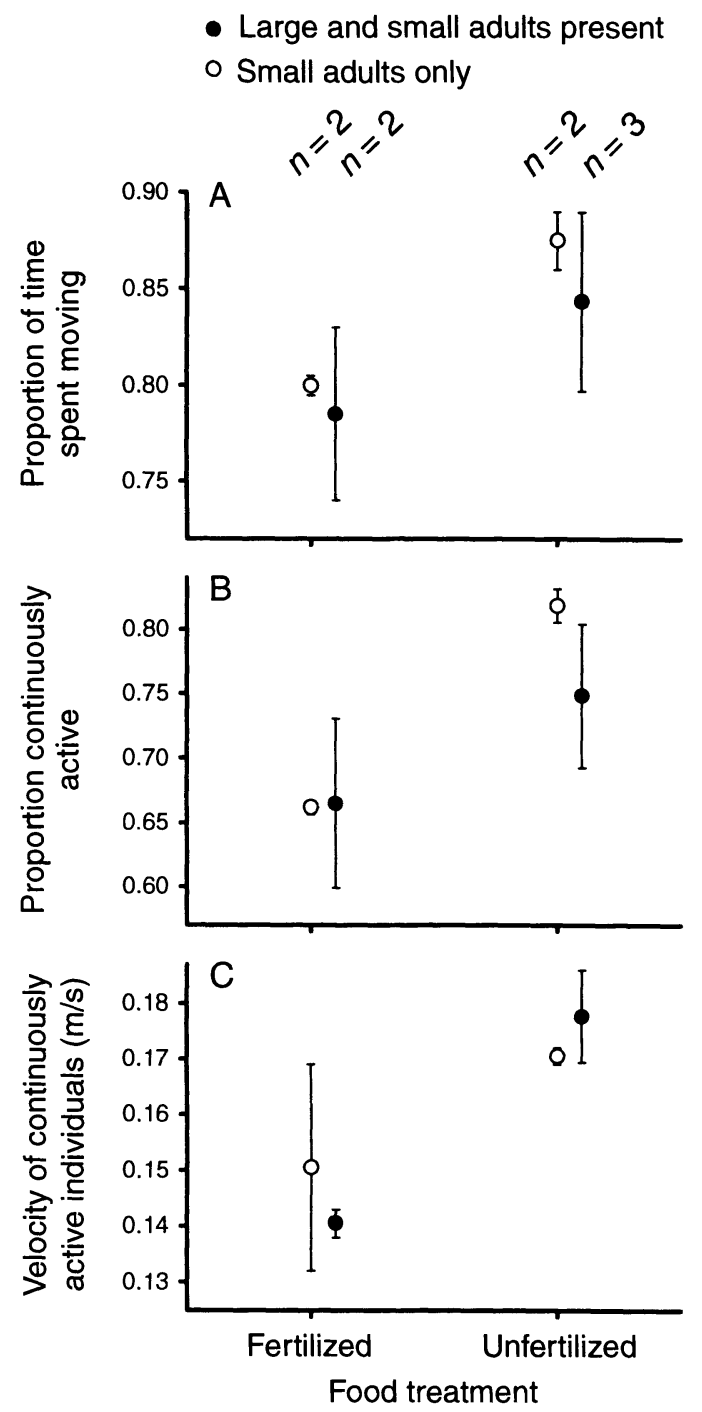

FIG. 3. Mean measures of individual age- 0 trout activity as a function of food treatment: (a) proportion of time spent moving; (b) proportion of each age- 0 cohort swimming continuously; (c) speed of continuously active individuals. Error bars indicate $\pm 1 \mathrm{SE}$. Sample size for each estimate on the raw data is given.

in all cases). Habitats $<1.5 \mathrm{~m}$ deep appear to represent a partial refuge to age- 0 trout from predation, given that not a single observation of an adult trout was made in this habitat over the course of 185,5 -min replicate observations among all lakes.

\section{Activity and habitat use of age-0 trout}

Individual age- 0 trout were less active in fertilized lakes, where daphnid food was more abundant, than in unfertilized lakes (Fig. 3). Young trout spent a smaller proportion of time moving in fertilized than in unfertilized lakes $\left(\chi_{1}^{2}=4.1, P<0.045 ;\right.$ Fig. 3A $)$; time spent moving was not, however, significantly related to adult trout size-structure or the interaction $\left(\chi_{1}^{2}=0.4\right.$ and
0.07 , respectively, $P>0.50$ ). Within each population we observed wide variation in the proportion of time spent moving by age- 0 trout, ranging from individuals holding station near the substrate to those swimming continuously in the water column. However, age-0 trout that did not swim continuously swam slowly and with little variation in speed compared to individuals swimming continuously and moving at high and variable speed. The proportion of each cohort that was continuously active was smaller in fertilized than in unfertilized lakes $\left(\chi_{1}^{2}=31, P<0.0001\right.$; Fig. 3B) but did not vary with either adult trout size-structure or the interaction $\left(\chi_{1}^{2}=0.5\right.$ and 3.9 , respectively, all $P>$ $0.05)$. Furthermore, the speed of age- 0 trout that swam continuously was significantly lower in fertilized than in unfertilized lakes $\left(\chi_{1}^{2}=8.6, P<0.005\right.$; Fig. 3C) but did not vary significantly with adult trout sizestructure or the interaction (all $P>0.25$ ).

Age- 0 trout used shallow habitats to a greater extent in high-food lakes than in low-food lakes during early summer (Fig. 4). In fact, there was little or no use of the two deepest habitats by age- 0 trout in high-food lakes, in contrast to that observed in low-food lakes in July (Fig. 4). Age-0 used shallow habitats to a greater extent than deep habitats in all populations in July $\left(\chi_{1}^{2}=35, P<0.0001\right)$, early August $\left(\chi_{1}^{2}=45, P<\right.$ $0.0001)$, and late August $\left(\chi_{1}^{2}=12, P<0.005\right)$. However, age- 0 trout used deep habitats to a lesser extent in high-food lakes than in low-food lakes in July $\left(\chi_{1}^{2}\right.$ $=18, P<0.0005)$ and in early August $\left(\chi_{1}^{2}=13, P<\right.$ 0.002; Fig. 4). By late August, however, patterns of space-use were similar between food treatments $\left(\chi_{1}^{2}=\right.$ 1.0, $P>0.50$; Fig. 4). All other main effects and interaction effects had no effect on age- 0 trout space-use $\left(\chi_{1}^{2}<4\right.$ and $P>0.15$ in all cases).

There were no clear trends in the size of age- 0 trout captured in different depths. Age-0 trout were significantly smaller in deeper habitats in one low-food lake $\left(\mathrm{CP} 1: F_{2,108}=3.8, P<0.05\right)$, but no significant effect of habitat on body size was found in any of the remaining populations (all $P>0.30$ ).

\section{Growth}

Mean mass of age- 0 trout increased rapidly over the season, but did not differ among treatments during the summer when differences in activity and habitat use were observed between food treatments (Fig. 5). Fork length of age- 0 trout in late July ranged from 28 to 55 $\mathrm{mm}$; mean mass of age- 0 trout at this time did not vary with fertilization treatment, adult trout size-structure, or the interaction $\left(\chi_{1}^{2}=0.10,0.14\right.$, and 0.02 , respectively, $P>0.70$ for each). By late August, age- 0 trout were between 35 and $85 \mathrm{~mm}$ in length; mean mass at this point in time was, again, unrelated to our experimental treatments $\left(\chi_{1}^{2}>0.42\right.$ and $P>0.50$ in each case).

Mean mass of age- 0 trout in early October was not related to the fertilization or adult trout size-structure 


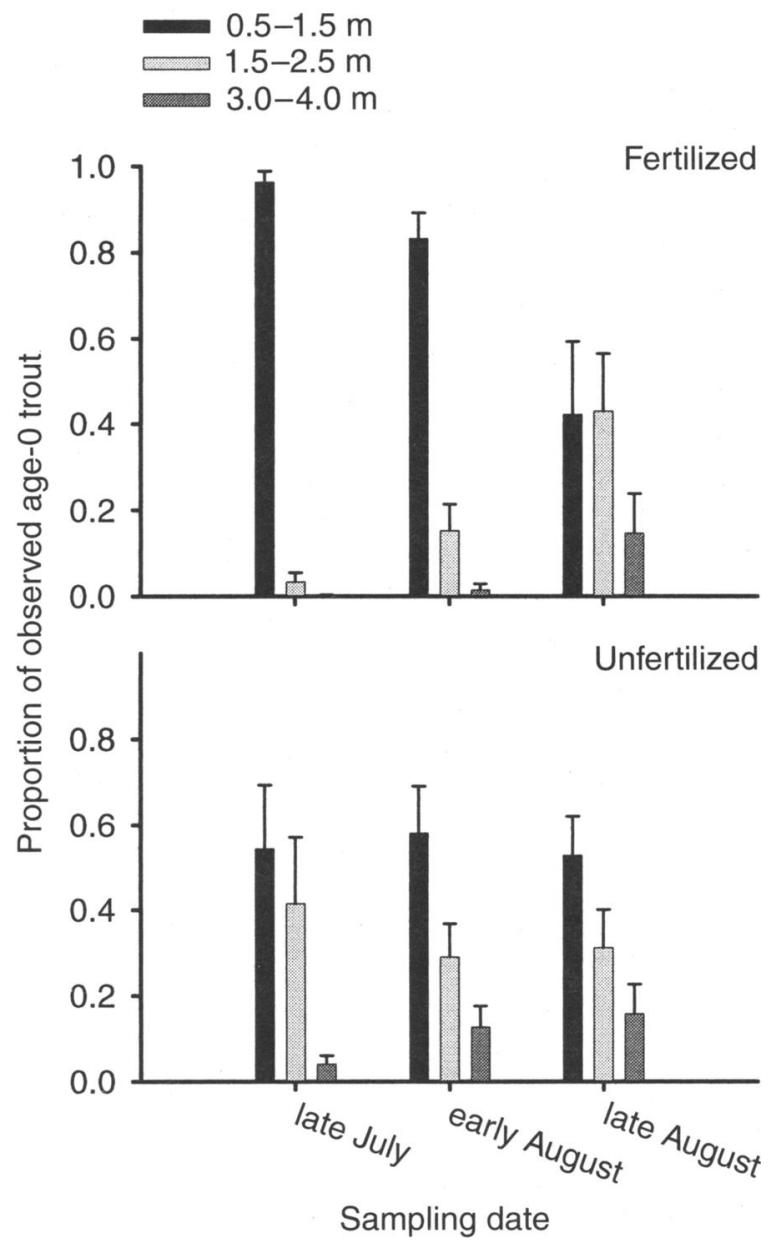

FIG. 4. Mean proportion of age-0 trout observed by snorkeling at different depths in late July, early August, and late August in relation to food treatment. Error bars indicate +1 SE. Sample sizes for each estimate on the raw data is given, averaged across the adult trout treatment.

manipulations $\left(\chi_{1}^{2}=3.3\right.$ and 2.9 , respectively, $P>0.06$ in each case). However, the near-significant $45 \%$ increase of fall body mass in the fertilization treatment (Fig. 5, $P=0.065$ ) suggests that food abundance influences autumn growth rate. When we related the actual mean daphnid biomass in each lake to the population mean mass of age- 0 trout, we found that mass of age-0 trout was significantly higher in lakes with greater pelagic daphnid biomass $\left(\chi_{1}^{2}=6.1, P<0.015\right)$ but was not related to either nearshore or deep littoral daphnid biomass $\left(\chi_{1}^{2}=0.48\right.$ and 0.76 , respectively, $P$ $>0.35$ for each). This pelagic food-dependent pattern of growth late in the season coincides with the use of deep habitats by age- 0 trout in late August (see Activity and habitat use of age-O trout) and observations of young trout in the pelagic habitat in September (P. A. Biro, personal observation).

\section{Mortality}

Higher activity and greater use of deep habitats by age-0 trout in unfertilized lakes was associated with

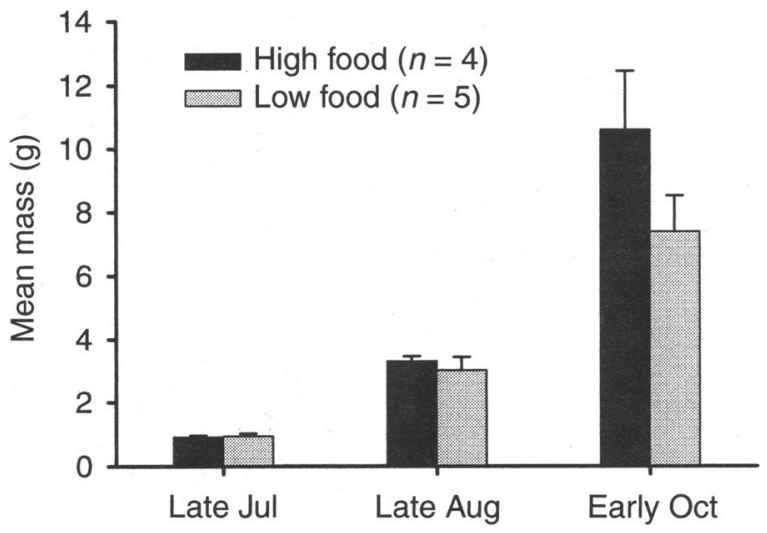

FIG. 5. Mean mass of age- 0 trout in relation to sampling date and food treatment. Error bars indicate +1 SE. Sample size for each estimate on the raw data is given, averaged across the adult trout treatment.

higher mortality estimated at the end of the growing season (Fig. 6). Mortality of age-0 trout was strongly and significantly related to the fertilization treatment $\left(\chi_{1}^{2}=19, P<0.0001\right)$, which was the most likely of the experimental factors predicting mortality $\left(\Delta_{i}=0\right)$; adult trout size-structure and the interaction were not significant predictors $\left(\chi_{1}^{2}=2.6\right.$ and 0.01 , respectively, both $P>0.10$ ). Lake fertilization explained $85 \%$ of the variation in age- 0 trout mortality whereby the predicted mean mortality of age- 0 trout in high-food lakes was only $58 \%$ in comparison to $75 \%$ mortality in lowfood lakes. Although our manipulation of adult trout size-structure was not a significant predictor using the likelihood ratio test, $\mathrm{AIC}_{\mathrm{c}}$ statistics indicate that both

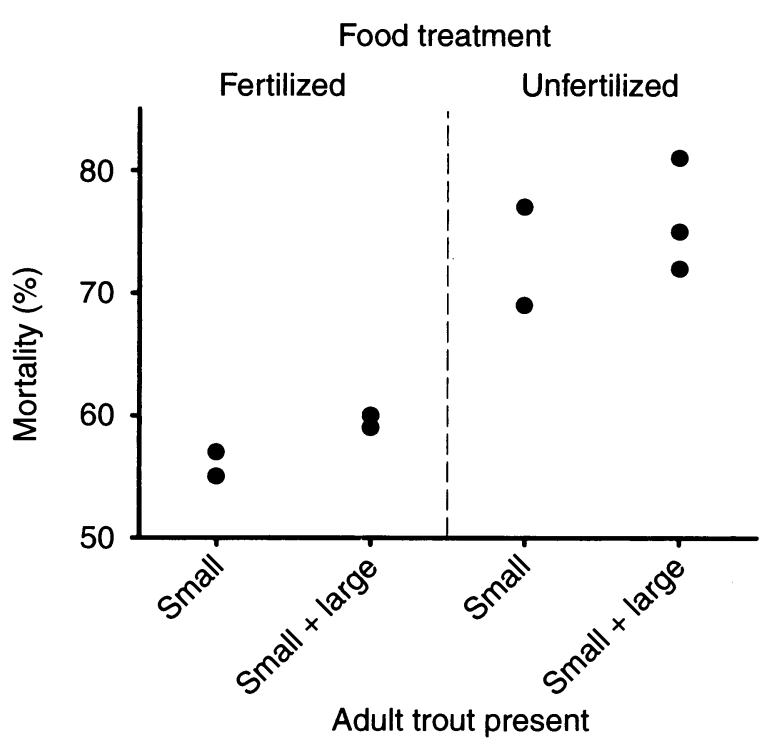

FIG. 6. Mortality estimates of age-0 trout in relation to food treatment and adult trout size-structure in nine experimental populations. Individual mortality estimates from each lake are presented. 
lake fertilization and adult trout size-structure independently affect age- 0 trout mortality $\left(\Delta_{i}=2.2\right.$; Fig. $6)$; there was no support for an interaction effect $\left(\Delta_{i}\right.$ $=9.4$ ). The additional presence of large adults in the full size-structure treatment had a relatively small effect, raising age- 0 trout mortality by $4 \%$ and increasing the percent variance explained from 84.7 to $88.5 \%$ (Fig. $6)$.

\section{Discussion}

We predicted that if risk to predation for age- 0 trout is a function of activity and habitat use, and it involves a trade-off with acquiring food, then activity and risky habitat use should be reduced at higher food abundance and greater risk to predation. The predictions for fooddependent behavior were supported by a chain of evidence linking behavior to food abundance. First, fertilization successfully increased the abundance of Daphnia, which are the major food item of age-0 trout. Second, activity of individual age-0 trout was lower in lakes where food was more abundant, which is consistent with the hypothesis that risk to predation is a function of activity. Third, age- 0 trout restricted their habitat use to shallower areas where food densities were lower but older trout were rarely found, which is consistent with risk being a function of habitat (depth). This trend was more pronounced when food abundance was increased, suggesting that age- 0 trout are more risk averse when food density is higher. Activity and habitat use of age- 0 trout did not differ among lakes with different size-structures of older trout. These observations, coupled with the observation that the spatial behavior of adult trout did not differ among treatments, suggests that our manipulation of adult trout was not successful in creating significant variation in risk among lakes, but that there was substantial spatial variation in risk within lakes.

We also predicted that age- 0 trout would experience higher growth in lakes with more abundant food. However, growth rates of age- 0 trout did not differ among treatments during the summer when age- 0 trout were primarily in nearshore habitats and differences in activity were observed. In July and August, it appears that large differences in nearshore Daphnia abundance between treatments was not sufficient to produce differences in growth rates. By October, the mean mass of survivors was higher in lakes with more abundant pelagic daphnid food. Most of this divergence occurred during September when age- 0 trout made extensive use of deep-water habitats where food differed between treatments by less than a factor of three. The lack of difference in growth among treatments suggests that small fish (with high mortality rates) take advantage of high food densities to reduce risk and increase survival. As such, age-0 trout appear to be strong risk minimizers. In contrast, larger fish (with low mortality rates, later in the season) are able to use high food densities in the pelagic habitat to increase growth.
Finally, if the trade-off between growth and mortality rates is mediated by activity and habitat use for age- 0 trout, then we expected that lower activity and use of shallow habitats by age- 0 trout in fertilized lakes would be associated with lower mortality. Mortality of age- 0 trout was markedly lower in fertilized lakes with more abundant food, and the fertilization treatment had high explanatory power for predicting age- 0 trout mortality. In terms of survivorship, age- 0 trout had $68 \%$ higher survival in lakes with more food than in lakes with less food (6300 compared to 3750 survivors/ha). If our manipulation of adult trout size-structure lowered activity and habitat use, we would have predicted lower mortality in lakes with large trout. However, it seems that our manipulation was a weak one. Given the lack of risk effects between lakes, then the slightly higher age0 trout mortality observed in lakes with large adults can be attributed to the fact that large trout are more efficient predators (e.g., Lynott et al. 1995), or simply due to the greater overall density of predators in lakes with large trout (365 vs. 300 predators/ha).

Our study supports the hypothesis that, at the wholesystem level, the trade-off between acquiring food and avoiding predators is mediated by individual behavior of age- 0 trout, and that the variation in behavior has large population-level consequences in terms of mortality, as analytical and optimization models would suggest (e.g., Werner et al. 1983, Werner and Anholt 1993, McNamara and Houston 1994). We predicted that increased activity and use of deeper habitats by age- 0 trout should increase intake rates of sedentary daphnid zooplankton, but also increase vulnerability to predation by adult trout. Higher activity and greater use of deep habitats by age- 0 trout in low-food lakes appeared to increase food intake rates and compensate for the lower food abundance, as suggested by the fact that mean mass of age- 0 trout did not differ among food treatments during the same period. Increased activity and use of deep habitats came with a large mortality cost to age- 0 trout, as predicted. These results are consistent with previous smaller scale studies, which suggest that habitat use of prey fish in lakes represents a trade-off between growth and morality rates (e.g., Werner et al. 1983, Werner and Hall 1988). Earlier studies in our study lakes suggested that habitat use by age- 0 trout involves a trade-off between growth (high daphnid abundance in deep habitats) and mortality rates (more trout predators in deep habitats [Landry 1997, Biro et al. 2003]). However, this is the first time we have found evidence suggesting that activity also has a mortality cost for age- 0 trout.

It is possible that fish in high-food lakes are growing at maximum rates, and therefore do not need to move more, whereas fish in low-food lakes must take greater risks to achieve the same growth rates. Indeed, earlier work in our lakes suggests that when food abundance is relatively high, similar to our high-food treatment, age-0 trout growth rates are maximal (Biro et al. 2003). 
If so, this is in contrast to our prediction for a reduction in foraging effort of age- 0 trout relative to fish in lowfood lakes. However, our conclusion that greater foraging effort in response to lower food abundance leads to greater predation mortality nonetheless remains valid. Again, equal apparent growth rates between the food treatments suggest that fish in low-food lakes increase foraging effort, and therefore risk to predation, in order to maintain high or maximal growth rates early in the season. Using the mean mass of survivors as an estimate of growth rate is potentially confounded in part by reduced fish densities in low-food lakes that experience higher mortality rates. However, if there is strong selection for rapid growth to avoid size-dependent risk of predation and to avoid starvation-related mortality over winter (see paragraphs below), then growth compensation through increased foraging effort and risk-taking is expected and would account for equal growth rates intially when fish are small and have low impact on their food resources (see Post et al. 1999).

Based upon the observed food-dependent behavioral responses, we infer that greater activity and use of deeper habitats by age- 0 trout in lakes with low food abundance respresent individual risk-taking. We expected greater risk taking by age- 0 trout when food is relatively scarce, because individuals must accumulate sufficient reserves to survive periods of overwinter starvation, while operating under the time constraint of a short growing season (see McNamara and Houston 1994, Post and Parkinson 2001). Indeed, young trout stocked into our lakes in late autumn experience $>90 \%$ mortality over the winter, when their mean mass is 2 $\mathrm{g}$ (and therefore they have low lipid reserves, in contrast to only $55 \%$ mortality for individuals with mean mass of $7.5 \mathrm{~g}$ and larger lipid reserves (Biro 2003). Similarly, experiments show that larval frogs originating from temporary ponds display greater risk-taking behavior than those from permanent ponds, due to the time constraint on growth to metamorphosis in a temporary pond (Anholt et al. 2000). In addition, we expected risk-taking because there is likely to be a mortality cost for being small and vulnerable that is independent of behavior (i.e., background mortality [Werner and Anholt 1993]) and therefore mortality would be related to time spent in a vulnerable small size class. For instance, smaller age- 0 trout are more vulnerable to predation than larger age-0 trout (e.g., Johnsson 1993, Landry 1997), and therefore individuals with faster growth should be vulnerable to predation for a shorter period of time (e.g., Werner et al. 1983, Werner and Gilliam 1984, Tonn et al. 1992).

An unavoidable consequence of increased system productivity in our experiment was reduced water clarity, which may suggest alternate explanations for our results. For instance, adult trout predators may be better able to detect age-0 trout in the clearer low-food lakes. However, if predation risk is higher due to increased clarity, then we would expect this to lower risky habitat use and reduce activity in low-food lakes, making apparent risk-taking more similar between food treatments. Therefore, the observed differences in activity and habitat use between food treatments due solely to food abundance, is likely conservative. However, this scenario would overestimate our assessment of the contribution of behavioral variation to mortality. It is also possible that age- 0 trout may better see adult trout and avoid those areas independent of any decisions that involve trade-offs with food. Again, if that were the case, we would expect to see fewer fish in deeper habitats in our low-food lakes, but this was not the case.

Our data indicate that behavioral changes can directly affect mortality rates without any change in the density or behavior of the predators. Previous studies examining mortality of young prey fish have shown that mortality is a size- or growth-rate-dependent process (e.g., Persson et al. 1996, Post et al. 1999, and reviews therein). In direct contrast to such studies, our data indicate that age- 0 trout mortality cannot be explained by differences in growth rate during the first two-thirds of the season when the young fish are most vulnerable to predation. The fact that mean mass of age- 0 trout during summer did not differ among treatments, while the variation in risk-taking varied dramatically among food treatments, indicate that predation mortality depends largely upon food-dependent risk-taking per se. If so, then prey fish mortality is largely under the "control" of the prey fish rather than dependent upon predator density or predator behavior (see Abrams 1993b). This assertion may be supported, in part, by the strong food effect on age- 0 trout mortality $\left(R^{2}=0.85\right)$, but weak effect of predator density/ size-structure $\left(R^{2}=0.04\right)$. Although our weak predator manipulation could explain the weak predator effect, previous experiments in our study lakes indicate that while the presence of adult trout has a very strong effect on age- 0 trout behavior and survival (Landry et al. 1999, Biro et al. 2003), additional predatory trout have little or no additional effect on survival (Post et al. 1999). This is not to say that predators are not important, but rather that food-dependent risk taking is the proximate factor and determines the availability of vulnerable prey to predators; the prey are consumed equally well by few or many predators.

Our whole-system scale observations of prey antipredator behavior match theoretical expectations and qualitatively match smaller scale empirical observations as well (e.g., Werner et al. 1983, Werner and Anholt 1993, Anholt and Werner 1995, 1998; see review in Diehl and Eklov 1995). Demonstrating that flexible antipredator behavior also exists at natural spatiotemporal scales is essential, since experiments conducted at smaller scales can overestimate the strength of behavioral responses to predation and therefore also overestimate growth and mortality consequences (see Lima 1998). In addition to food-sensitive behavior, age- 0 trout also appeared to be sensitive to their size- 
related vulnerability to predation. For instance, age- 0 trout used deep habitats to a significant extent in late summer in all lakes, and we observed young trout jumping at the surface in the open pelagic habitat in September (P. A. Biro et al., personal observation). This suggests that they take advantage of reduced risk due to their larger body size (i.e., greater evasion ability; Johnsson 1993; see also Taylor and McPhail 1985 , Lundvall et al. 1999), move to more productive habitats, and increase growth.

Behavioral ecologists have long asserted that variation in antipredator behavior must have consequences for population dynamics if it affects critical rates such as growth, birth, and death (see Anholt 1997). However, empirical evidence for the population consequences of behavior are rarely demonstrated and remain largely inferred (Lima 1998). Here, we provide evidence that it is possible to predict the mortality of prey populations at the scale of whole systems with a relatively simple notion of how prey trade off growth and mortality rates, via their foraging behavior. The relatively high degree of realism of our experiments should allow our results to be more readily extropolated to natural situations than previous studies. If so, then our study represents an intermediate empirical test of the importance of behavior in populations, lying somewhere between small scale experiments, which fall short of directly linking individuals and populations, and the empirically unknown effects of individual behavior on population dynamics in vertebrate populations. Therefore, the mechanisms of prey mortality explored and supported here warrant further study and inclusion into mechanistic models linking individual behavior to population-level dynamics, given the widespread nature of activity- and habitat-mediated trade-offs between growth and mortality rates in diverse animal taxa (Helfman 1990, Werner and Anholt 1993, Lima 1998).

Although we have provided evidence that behavior can play an important role in determining variation in mortality among prey populations at a realistic scale, it is difficult to say to what extent population dynamics may be affected. Theoretical studies suggest that, in many but not all cases, variation in behavior does affect population dynamics (e.g., Fryxell and Lundberg 1997, Schmitz 2001, De Roos et al. 2002). Whether or not the observed trade-off will have consequences for population dynamics has yet to be determined and will likely need to be explored with models, given the logistical difficulties that an empirical test at this scale would pose. We speculate that the large differences in age- 0 trout survival to autumn, and the differences in mean mass by autumn due to differences in food availability, are together likely to affect dynamics given size-dependent overwinter survival and strong densitydependent growth depression of age-1 trout that will affect the cohort in the following season (Post et al. 1999). Finally, we echo the viewpoint of Schmitz (1998) that ecologists might gain a better and more mechanistic understanding of populations and communities with a more forceful linkage between behavioral and population ecology theory and approaches.

\section{ACKNOWLEDGMENTS}

Many thanks to Cory Corbett, Ashley Morton, and especially Fiona Johnston for their field assistance, and to Christa Beckmann for assistance with laboratory analyses. This research was supported by NSERC Strategic and Operating grants to J. R. Post and by the government of British Columbia to E. A. Parkinson. P. A. Biro was supported by an NSERC Postgraduate Scholarship. Special thanks to the staff at the Fraser Valley Fish Hatchery for their help with fall netting, stocking, and their willingness to accommodate my needs. We also thank Rob McLaughlin, Lennart Persson, and two anonymous reviewers for their helpful comments on an earlier draft of this manuscript.

\section{Literature Cited}

Abrams, P. A. 1984. Foraging time optimization and interactions in food webs. American Naturalist 124:80-96.

Abrams, P. A. 1990. The effects of adaptive behavior on the type-2 functional response. Ecology 71:877-885.

Abrams, P. A. 1991. The relationship between food availability and foraging effort: effects of life history and time scale. Ecology 72:1242-1252.

Abrams, P. A. 1993a. Optimal traits when there are several costs: the interaction of mortality and energy costs in determining foraging behavior. Behavioural Ecology 4:246253.

Abrams, P. A. $1993 b$. Why predation rate should not be proportional to predator density. Ecology 74:726-733.

Anholt, B. R. 1997. How should we test for the role of behaviour in population dynamics? Evolutionary Ecology 11: 633-640.

Anholt, B. R., and E. E. Werner. 1995. Interaction between food availability and predation mortality mediated by adaptive behavior. Ecology 76:2230-2234.

Anholt, B. R., and E. E. Werner. 1998. Predictable changes in predation mortality as a consequence of changes in food availability and predation risk. Evolutionary Ecology 12: 729-738.

Anholt, B. R., E. E. Werner, and D. K. Skelly. 2000. Effect of food and predators on the activity of four larval ranid frogs. Ecology 81:3509-3521.

Beckerman, A. P., M. Uriarte, and O. J. Schmitz. 1997. Experimental evidence for a behavior-mediated trophic cascade in a terrestrial food chain. Proceedings of the National Academy of Sciences (USA) 94:10735-10738.

Biro, P. A. 1996. Space-use by juvenile brook charr (Salvelinus fontinalis) in lakes: the central-place territorial model does not apply. M.S. Thesis. University of Guelph, Guelph, Ontario, Canada.

Biro, P. A. 2003. Population consequences of behaviorally mediated tradeoffs between growth and mortailty in age-0 rainbow trout (Oncorhychus mykiss) cohorts. Ph.D. Dissertation. University of Calgary, Calgary, Alberta, Canada.

Biro, P. A., J. R. Post, and E. A. Parkinson. 2003. Population consequences of a predator-induced habitat shift by trout in whole-lake experiments. Ecology 84:691-700.

Biro, P. A., and M. S. Ridgway. 1995. Individual variation in foraging movements in a lake population of young-ofthe-year brook charr (Salvelinus fontinalis). Behaviour 120: $1-12$.

Biro, P. A., M. S. Ridgway, and D. L. G. Noakes. 1997. The central-place territorial model does not apply to space-use by juvenile brook charr (Salvelinus fontinalis) in lakes. Journal of Animal Ecology 66:837-845. 
Burnham, K. P., and D. R. Anderson. 1998. Model selection and inference: a practical information-theoretic approach. Springer-Verlag, New York, New York, USA.

Carpenter, S. R. 1996. Microcosm experiments have limited relevance for community and ecosystem ecology. Ecology 77:677-680.

De Roos, A. M., K. Leonardsson, L. Persson, and G. G. Mittelbach. 2002. Ontogenetic niche shifts and flexible behavior in size-structured populations. Ecological Monographs 72:271-292.

De Roos, A. M., and L. Persson. 2001. Physiologically structured models-from versatile technique to ecological theory. Oikos 94:51-71.

Diehl, S., and P. Eklov. 1995. Effects of piscivore-mediated habitat use on resources, diet, and growth of perch. Ecology 76:1712-1726.

Dill, L. M., and A. H. G. Fraser. 1984. Risk of predation and the feeding behavior of juvenile coho salmon (Oncorhynchus kisutch). Behavioral Ecology and Sociobiology 16: 65-71.

Dunbrack, R. L., and L. A. Giguere. 1987. Adaptive responses to accelerating costs of movement: a bioenergetic basis for the type-III functional response. American Naturalist 130: $147-160$.

Fryxell, J. M., and P. Lundberg. 1997. Individual behavior and community dynamics. Chapman and Hall, New York, New York, USA.

Grant, J. W., and D. L. G. Noakes. 1987. Movers and stayers: foraging tactics of young-of-the-year brook charr, Salvelinus fontinalis. Journal of Animal Ecology 56:1001-1013.

Helfman, G. S. 1990. Mode selection and mode switching in foraging animals. Advances in the Study of Behavior 19:249-298

Hilborn, R., and M. Mangel. 1997. The ecological detective: confronting models with data. Princeton University Press, Princeton, New Jersey, USA.

Huang, C., and A. Sih. 1991. Experimental studies on direct and indirect interactions in a three- trophic-level system. Oecologia 85:530-536.

Johnsson, J. 1993. Big and brave: size selection affects foraging under risk of predation in juvenile rainbow trout, Oncorhynchus mykiss. Animal Behaviour 45:1219-1225.

Landry, F. 1997. Direct and indirect effects of interference competition in size-structured rainbow trout (Oncorhynchus mykiss) populations. Thesis. University of Calgary, Calgary, Alberta, Canada.

Landry, F., J. R. Post, and E. A. Parkinson. 1999. Spatial ontogeny of lentic age-0 rainbow trout, Oncorhynchus mykiss: whole lake manipulations of population size structure. Canadian Journal of Fisheries and Aquatic Sciences 56: 1916-1928.

Lima, S. L. 1998. Stress and decision-making under the risk of predation: recent developments from behavioral, reproductive, and ecological perspectives. Advances in the Study of Behavior 27:215-290.

Lima, S. L., and P. A. Zollner. 1996. Towards a behavioral ecology of ecological landscapes. Trends in Ecology and Evolution 11:131-135.

Lundvall, D., R. Svanback, L. Persson, and P. Bystrom. 1999. Size-dependent predation in piscivores: interactions between predator foraging and prey avoidance abilities. Canadian Journal of Fisheries and Aquatic Sciences 56:12851292.

Lynott, S. T., S. D. Bryan, T. D. Hill, and W. G. Duffy. 1995. Monthly and size-related changes in the diet of rainbow trout in Lake Oahe, South Dakota. Journal of Freshwater Ecology 10:399-407.

Martel, G., and L. M. Dill. 1995. Influence of movement by coho salmon (Oncorhynchus kisutch) parr on their detection by common mergansers (Mergus merganser). Ethology 99: 139-149.

McLaughlin, R. L., J. W. A. Grant, and D. L. Kramer. 1994. Foraging movements in relation to morphology, water-column use, and diet for recently-emerged brook trout (Salvelinus fontinalis) in still-water pools. Canadian Journal of Fisheries and Aquatic Sciences 51:268-279.

McNamara, J. M., and A. I. Houston. 1987. Starvation and predation as factors limiting population size. Ecology 68 : 1515-1519.

McNamara, J. M., and A. I. Houston. 1994. The effect of a change in foraging options on intake rate and predation rate. American Naturalist 144:978-1000.

Metcalfe, N. B., F. A. Huntingford, and J. E. Thorpe. 1987. The influence of predation risk on the feeding motivation and foraging strategy of juvenile Atlantic salmon. Animal Behaviour 35:901-911.

Peckarsky, B. L., and A. R. McIntosh. 1998. Fitness and community consequences of predator-induced changes in mayfly behavior. Oecologia 113:565-576.

Persson, L., J. Andersson, E. Wahlstrom, and P. Eklov. 1996. Size-specific interactions in lake systems: predator gape limitation and prey growth rate and mortality. Ecology 77: 900-911.

Persson, L., P. Bystrom, E. Wahlstrom, J. Andersson, and J Hjelm. 1999. Interactions among size-structured populations in a whole-lake experiment: size- and scale-dependent processes. Oikos 87:139-156.

Post, J. R. 1984. Planktivorous fish and the structure of pelagic plankton communities. Thesis. York University, Toronto, Ontario, Canada.

Post, J. R., and E. A. Parkinson. 2001. Energy allocation strategy in young fish: allometry and survival. Ecology 82 : 1040-1051.

Post, J. R., E. A. Parkinson, and N. T. Johnston. 1998. Spatial and temporal variation in risk to piscivory of age- 0 rainbow trout: patterns and population consequences. Transactions of the American Fisheries Society 127:932-942.

Post, J. R., E. A. Parkinson, and N. T. Johnston. 1999. Density-dependent processes in structured fish populations: assessment of interaction strengths in whole-lake experiments. Ecological Monographs 69:155-175.

SAS Institute. 1998. SAS/STAT user's guide. Version 8.0 Volume 1. SAS Institute, Cary, North Carolina, USA.

Schmitz, O. J. 1998. Direct and indirect effects of predation and predation risk in old-field interaction webs. American Naturalist 151:327-342.

Schmitz, O. J. 2001. From interesting details to dynamical relevance: toward more effective use of empirical insights in theory construction. Oikos 94:39-50.

Sutherland, W. J. 1996. From individual behaviour to population ecology. Oxford University Press, Oxford, UK.

Taylor, E. B., and J. D. McPhail. 1985. Burst swimming and size-related predation of newly emerged coho salmon $\mathrm{On}$ corhynchus kisutch. Transactions of the American Fisheries Society 114:546-551.

Tonn, W. M., C. A. Paszkowski, and I. J. Holopainen. 1992. Piscivory and recruitment: mechanisms structuring prey populations in small lakes. Ecology 73:951-958.

Turner, A. M., and G. G. Mittelbach. 1990. Predator avoidance and community structure: interactions among piscivores, planktivores and plankton. Ecology 71:2241-2254.

Walters, C. J., and F. Juanes. 1993. Recruitment limitation as a consequence of natural selection for use of restricted feeding habitats and predation risk taking by juvenile fishes. Canadian Journal of Fisheries and Aquatic Sciences 50: 2058-2070.

Werner, E. E., and B. R. Anholt. 1993. Ecological consequences of the trade-off between growth and mortality rates mediated by foraging activity. American Naturalist 142: 242-272. 
Werner, E. E., and B. R. Anholt. 1996. Predator-induced behavioral indirect effects: consequences to competitive interactions in anuran larvae. Ecology 77:157-169.

Werner, E. E., and J. F. Gilliam. 1984. The ontogenetic niche shift and species interactions in size-structured populations. Annual Review of Ecology and Systematics 15:393-425. Werner, E. E., J. F. Gilliam, D. J. Hall, and G. G. Mittelbach
1983. An experimental test of the effects of predation risk on habitat use in fish. Ecology 64:1540-1548.

Werner, E. E., and D. J. Hall. 1988. Ontogenetic habitat shifts in bluegill: the foraging rate-predation risk trade-off. Ecology 69:1352-1366.

Wetzel, W. 1983. Limnology. Saunders, New York, New York, USA. 